\title{
Condições de trabalho de professores e diretores de escolas públicas: um estudo sobre a rede estadual de educação do Rio Grande do Sul
}

\author{
Working conditions of public-school teachers and principals: a study on the \\ Rio Grande do Sul (Brazil) state network
}

\author{
Juliana Hass Massena ${ }^{l}$ \\ Mateus Saraiva ${ }^{2}$ \\ Juliana Maciel de Souza Lamers ${ }^{3}$ \\ Maria Beatriz Luce ${ }^{4}$
}

\begin{abstract}
RESUMO
O presente artigo analisa as condições de trabalho dos professores e diretores das escolas estaduais do Rio Grande do Sul. É resultado de pesquisa exploratória, tendo como fonte principal os questionários do SAEB (2015b, 2017b), com referencial acerca dos profissionais, suas carreiras e valorização, produzido por Oliveira (2004), Souza (2007), Souza e Gouveia (2010), Jacomini e Penna (2016) e Nunes e Oliveira (2017) mais os estudos de Ball, Maguire e Braun (2016) sobre a atuação das políticas, e Nancy Fraser (2006) sobre justiça social. Diretores da rede estadual gaúcha possuem melhores condições de trabalho do que os professores da mesma rede: possuem salários um pouco maiores; têm carga horária semanal de até 40 horas $(86,2 \%)$; declaram receber apoio dos superiores (84,1\% em 2015 e 85,4\% em 2017) e da comunidade (95\% em 2015 e 2017); todavia, parte exerce outra atividade remunerada $(30,5 \%)$. Os professores, além de elevada carga de trabalho, têm precários vínculos de carreira; sendo que 47,2\% atuam em duas ou mais escolas que possuem remuneração muito baixa; e $40 \%$ creditam aos fatores de insatisfação os problemas de aprendizagem dos alunos. Assim, evidenciamos a gravidade do problema de desvalorização da carreira e a necessidade de agregar tal situação à pauta das políticas educacionais.
\end{abstract}

Palavras-chave: Trabalho docente; Diretor de escola; Rio Grande do Sul; Escola estadual; SAEB.

\footnotetext{
${ }^{1}$ Pedagoga, Mestra em Educação, Doutoranda no Programa de Pós-Graduação em Educação da Universidade Federal do Rio Grande do Sul - UFRGS, Bolsista CAPES, Núcleo de Estudos de Política e Gestão da Educação, Faculdade de Educação. E-mail: jujuhass@ @mail.com

${ }^{2}$ Licenciado em História, Bacharel em Políticas Públicas, Mestre em Educação, Doutorando no Programa de Pós-Graduação em Educação da Universidade Federal do Rio Grande do Sul UFRGS, Bolsista CAPES, Núcleo de Estudos de Política e Gestão da Educação, Faculdade de Educação. E-mail: mateus.saraiva@ufrgs.br

${ }^{3}$ Pedagoga, Mestra em Ensino da Saúde, Doutoranda no Programa de Pós-Graduação em Educação da Universidade Federal do Rio Grande do Sul - UFRGS, Núcleo de Estudos de Política e Gestão da Educação, Faculdade de Educação. Técnica em Assuntos Educacionais na UFRGS. E-mail: juli.desouza@ufrgs.br

${ }_{4}^{4}$ Doutora em Educação, Professora Titular na Universidade Federal do Rio Grande do Sul UFRGS, Núcleo de Estudos de Política e Gestão da Educação, Faculdade de Educação. E-mail: lucemb@ufrgs.br
} 


\begin{abstract}
This article analyzes the working conditions of teachers and principals of Rio Grande do Sul state schools. It is the result of exploratory research based on the SAEB questionnaires (2015b, 2017b), with reference to professionals, their careers and appreciation, produced by Oliveira (2004), Souza (2007), Souza and Gouveia (2010), Jacomini and Penna (2016) and Nunes e Oliveira (2017) plus the studies of Ball, Maguire and Braun (2016) about the performance of policies and Nancy Fraser (2006) about social justice. Principals in the Rio Grande do Sul state school system have better working conditions than teachers at the same school system: they have slightly higher salaries. They have weekly workload of up to 40 hours $(86.2 \%)$. They declare receiving support from their superiors (84.1\% in 2015 and 85.4\% in 2017) and their communities (95\% in 2015 and 2017). However, part of them has another paid activity (30.5\%). Teachers, in addition to their high workload, have poorer career conditions: $47.2 \%$ of them work in two or more schools because of their extremely low pay, and $40 \%$ of the teachers admit that their students' learning problems are related to low job satisfaction. Thus, we highlight the severe implications of teachers' career devaluation and the need to address such major problem in the educational policies agenda.
\end{abstract}

Keywords: Teachers working conditions; School principal; Rio Grande do Sul; State School; SAEB. 


\section{Introdução}

Tempos de crise, tempos de disputa: a democratização da educação em xeque. Direitos e deveres sob revisionismo. Em defesa do direito à educação e do dever estatal de educar, cumpre dar atenção às condições efetivas para a aprendizagem e a gestão democrática. Examinar a situação das instituições escolares e seus profissionais, sob tal perspectiva, exige a compreensão de unidade na diversidade; de cada instituição como unidade do sistema educacional e lugar de realização do direito à educação que requer, como dever, ação pedagógica e administrativa planejada e colegiada.

Nesse sentido, na escola - onde o planejamento e a busca de soluções devem ocorrer de modo participativo consolida-se a possibilidade de valorização dos profissionais da educação. No entanto, a agenda políticoeducacional tem trazido à tona as limitações do processo participativo.

A possibilidade de participação de todos os segmentos de uma comunidade escolar nas instâncias de tomada de decisão, tais como conselho escolar ou conselho de educação, constitui-se num aspecto essencial da concretização de justiça social (FRASER, 2006). Os diferentes sujeitos da comunidade escolar devem ter espaço de participação, tendo vez e voz sobre as ações que impactam direta ou indiretamente nas suas vidas, independente de sua condição socioeconômica ou cultural. Serão todos afetados pela materialização das políticas educacionais, portanto, devem também ser partícipes desta construção.

Ball, Maguire e Braun (2016, p. 36) alertam que, em muitos estudos acadêmicos, "a política é desmaterializada", escolas em contextos diferentes possuem capacidades, potencialidades e limites diversos. Para eles, "a política é feita pelos e para os professores; eles são atores e sujeitos, sujeitos e objetos da política. A política é escrita nos corpos e produz posições específicas dos sujeitos" (BALL; MAGUIRE; BRAUN, p.13). O contexto material do exercício docente é um poderoso condicionante da cultura profissional e, por isso, dizemos, produz efeitos sobre como atuam na gestão democrática.

O momento político que vivemos no país nos tem ressaltado a fragilidade dos direitos conquistados nas últimas décadas e a invisibilidade que tínhamos da força de certas disputas latentes em fundamentos da política de democratização da educação: a consigna de prioridade à educação no orçamento público ${ }^{5}$; o controle sobre o conteúdo e materiais curriculares; a (des)valorização dos profissionais ${ }^{7} \mathrm{e}$

\footnotetext{
${ }^{5}$ ORÇAMENTO da Educação sofre corte de R\$ 5,83 bilhões. Andes. 2 de abril de 2019. Disponível em: https://bit.ly/2FUZM9q. Acesso: $19 / 12 / 19$.

${ }^{6}$ MINISTRO quer mudar livros didáticos para alterar visão da ditadura militar. Eu Estudante. 3 de abril de 2019. Disponível em: https://bit.ly/2IbqGM0. Acesso: 19/12/19.

7 POLÊMICA: professores estão quebrando o país. Avaliação Educacional - Blog do Freitas. Disponível em: https://bit.ly/2D7q6M3. Acesso: 19/12/19.
} 
sua liberdade de cátedra ${ }^{8}$; a legitimidade da gestão democrática e a autonomia político-pedagógica da escola. Neste quadro, ganham relevo discursos de desprofissionalização da carreira, incluindo aligeiramento da formação, intensificação do trabalho e desmedida responsabilização pelo desempenho escolar.

Com efeito, já em 2004, Oliveira apontava uma crescente responsabilização dos professores pela qualidade do ensino e uma forte crença no tecnicismo, além da sobrecarga de tarefas. Tais elementos, destacamos, potencializam a perda de autonomia da escola e a desvalorização social dos seus profissionais, ao remeterem a organização da escola a modelos gerencialistas e aporem ao educador a mera função de gestor do conhecimento e dos tempos de ensinar e aprender.

Os enfoques sobre a valorização docente são diversos e destacam: a importância da remuneração e da carreira correspondentes à formação exigida e às responsabilidades sociais implicadas, bem como das condições materiais de trabalho (GATTI, BARROSO, 2009), a diferença salarial entre docentes e profissionais da educação em cargos de direção (SOUZA, GOUVEIA, 2010); não existência de diferenças significativas no salário de homens e mulheres docentes, pois estas são devidas ao nível de formação e tempo de serviço (SOUZA, 2007; CORREA, 2010).

\footnotetext{
${ }^{8} \mathrm{MPF}$ pede que seis instituições federais de ensino do RS defendam professores de "censura”. Gaucházh - Educação e Trabalho. 21 de novembro de 2018. Disponível em: https://bit.ly/2P259a3. Acesso: 19/12/19.
}

Mais recentemente, Jacomini e Penna (2016, p.190) alertaram sobre a precarização das condições do magistério, dado que "a ausência da jornada de tempo integral e as múltiplas jornadas a que o professor se submete podem, por vezes, comprometer a qualidade do processo de ensino e de aprendizagem". Outrossim, Cunha (2014, p.794) realça que "tanto mais aproximam as condições de formação com as de trabalho, mais poderão ter sentido e significado nos contextos em que atua". Convergem estes autores sobre a relevância de diretores e professores se dedicarem a somente uma escola, com estabilidade, valorização salarial, adequada carreira docente e jornada de trabalho não-exaustiva. Logo, o contexto de trabalho correlaciona-se à qualidade nas condições da oferta educacional.

Sendo a educação escolar direito subjetivo e dever do Estado, a este cabe a responsabilidade de garantir adequadas condições de trabalho aos profissionais da docência, do apoio e da gestão escolar. Com essa premissa e nas delimitações da presente pesquisa, formulamos a questão central: Quais condições de exercício profissional dos diretores e professores da rede estadual gaúcha foram evidenciadas nos questionários do SAEB (2017)?

\section{Procedimentos metodológicos}

Motivados por essa questão, analisamos as condições de trabalho dos professores e diretores das escolas estaduais do Rio Grande do Sul a partir dos microdados coletados nos questionários do diretor e do professor do 
SAEB (BRASIL, 2017b) e de elementos do Censo da Educação Básica (BRASIL, 2017a).

Nesses questionários, encontram-se informações acerca da formação profissional, práticas gerenciais e pedagógicas, além do perfil socioeconômico e cultural dos diretores e professores. É importante destacar que os diretores e professores são respondentes diretos de tais instrumentos, o que permite alguns apontamentos para diagnóstico e, subsequentemente, dis- cussão sobre seus efeitos na gestão das escolas.

Com apoio no referencial teórico e na legislação pertinente (BRASIL, 1996; BRASIL, 2009), entendemos que a valorização dos profissionais da educação compreende duas dimensões: condições de trabalho, carreira e remuneração. Para fins deste artigo, produzimos e utilizaremos a seguinte categorização dos indicadores e questões estudadas (Quadro 1).

Quadro 1: Dimensões que compõem o estudo da valorização dos profissionais da educação dos professores e diretores da rede estadual de educação do Rio Grande do Sul

\begin{tabular}{|c|c|c|c|}
\hline Dimensão & Indicadores & Fonte & Questões \\
\hline \multirow{6}{*}{$\begin{array}{l}\text { Condições } \\
\text { de trabalho }\end{array}$} & $\begin{array}{l}\text { Esforço } \\
\text { docente }\end{array}$ & $\begin{array}{l}\text { Censo da Educa- } \\
\text { ção Básica }(2015 \text {, } \\
2017)\end{array}$ & $\begin{array}{l}\text { Número de escolas em que o professor leciona } \\
\text { Número de turnos de trabalho } \\
\text { Números de alunos para quem dá aula } \\
\text { Número de etapas de ensino }\end{array}$ \\
\hline & $\begin{array}{l}\text { Número de } \\
\text { escolas em } \\
\text { que trabalha }\end{array}$ & $\begin{array}{l}\text { Questionário do } \\
\text { Professor }(2015, \\
2017)\end{array}$ & Em quantas escolas você trabalha? \\
\hline & \multirow{2}{*}{$\begin{array}{l}\text { Carga horá- } \\
\text { ria de traba- } \\
\text { lho semanal }\end{array}$} & $\begin{array}{l}\text { Questionários do } \\
\text { Diretor e do Pro- } \\
\text { fessor (2017) }\end{array}$ & $\begin{array}{l}\text { Qual é a sua carga horária de trabalho semanal, } \\
\text { nesta escola? }\end{array}$ \\
\hline & & $\begin{array}{l}\text { Questionário do } \\
\text { Professor (2017) }\end{array}$ & $\begin{array}{l}\text { Considerando todas as escolas em que você } \\
\text { trabalha atualmente como professor, qual a sua } \\
\text { carga horária semanal? }\end{array}$ \\
\hline & $\begin{array}{l}\text { Exercício de } \\
\text { outra ativi- } \\
\text { dade que } \\
\text { contribui } \\
\text { para renda } \\
\text { pessoal }\end{array}$ & $\begin{array}{l}\text { Questionários do } \\
\text { Diretor e do Pro- } \\
\text { fessor (2017) }\end{array}$ & $\begin{array}{l}\text { Você exerce outra atividade que contribui para } \\
\text { sua renda pessoal? }\end{array}$ \\
\hline & $\begin{array}{l}\text { Condições } \\
\text { existentes } \\
\text { para o exer- } \\
\text { cício da } \\
\text { direção }\end{array}$ & $\begin{array}{l}\text { Questionário do } \\
\text { Diretor }(2015, \\
2017)\end{array}$ & $\begin{array}{l}\text { Condições existentes para o exercício do cargo } \\
\text { de diretor: } \\
\text { Há interferência de atores externos em sua } \\
\text { gestão? } \\
\text { Há apoio de instâncias superiores? } \\
\text { Há troca de informações com diretores de } \\
\text { outras escolas? } \\
\text { Há apoio da comunidade a sua gestão? }\end{array}$ \\
\hline
\end{tabular}




\begin{tabular}{|c|c|c|c|}
\hline & $\begin{array}{l}\text { Problemas } \\
\text { de funcio- } \\
\text { namento da } \\
\text { escola }\end{array}$ & $\begin{array}{l}\text { Questionário do } \\
\text { Diretor (2015, } \\
\text { 2017) }\end{array}$ & $\begin{array}{l}\text { O funcionamento da escola foi dificultado por } \\
\text { alguns dos seguintes problemas? } \\
\text { Insuficiência de recursos financeiros, inexis- } \\
\text { tência de professores para algumas disciplinas } \\
\text { ou séries, carência de pessoal administrativo, } \\
\text { carência de pessoal de apoio pedagógico, falta } \\
\text { de recursos pedagógicos, interrupção das ati- } \\
\text { vidades escolares, alto índice de faltas por } \\
\text { parte dos professores, alto índice de faltas por } \\
\text { parte dos alunos, alta rotatividade do corpo } \\
\text { docente, indisciplina por parte dos alunos. }\end{array}$ \\
\hline & $\begin{array}{l}\text { Percepção } \\
\text { dos professo- } \\
\text { res sobre } \\
\text { problemas de } \\
\text { aprendiza- } \\
\text { gem dos } \\
\text { alunos }\end{array}$ & $\begin{array}{l}\text { Questionário do } \\
\text { Professor (2017) }\end{array}$ & $\begin{array}{l}\text { Na sua percepção, os possíveis problemas de } \\
\text { aprendizagem dos alunos das série(s) ou ano(s) } \\
\text { avaliado(s) ocorrem, nesta escola, devido } \\
\text { à/ao(s): } \\
\text { Sobrecarga de trabalho dos professores, difi- } \\
\text { cultando o planejamento e o preparo das aulas? } \\
\text { Insatisfação e desestímulo do professor com a } \\
\text { carreira docente? }\end{array}$ \\
\hline \multirow{3}{*}{$\begin{array}{l}\text { Carreira e } \\
\text { remunera- } \\
\text { ção }\end{array}$} & $\begin{array}{l}\text { Idade - atra- } \\
\text { tividade }\end{array}$ & $\begin{array}{l}\text { Censo da Educa- } \\
\text { ção Básica (2017) }\end{array}$ & Data de nascimento \\
\hline & $\begin{array}{l}\text { Estudos de } \\
\text { graduação e } \\
\text { pós- } \\
\text { graduação }\end{array}$ & $\begin{array}{l}\text { Questionários do } \\
\text { Diretor e do Pro- } \\
\text { fessor (2017) }\end{array}$ & $\begin{array}{l}\text { Mais alto nível de escolaridade concluído (até } \\
\text { a graduação) } \\
\text { Curso de pós-graduação de mais alta titulação }\end{array}$ \\
\hline & $\begin{array}{l}\text { Remunera- } \\
\text { ção }\end{array}$ & $\begin{array}{l}\text { Questionários do } \\
\text { Diretor e Questi- } \\
\text { onário do Profes- } \\
\text { sor (2017) }\end{array}$ & $\begin{array}{l}\text { Como diretor, qual é, aproximadamente, o seu } \\
\text { salário bruto? (com adicionais, se houver). } \\
\text { Como professor, qual é, aproximadamente, o } \\
\text { seu salário bruto? (com adicionais, se houver). }\end{array}$ \\
\hline
\end{tabular}

Fonte: BRASIL, 2015b, 2015c, 2017a, 2017b, 2017c.

$\mathrm{Na}$ análise, consideramos como critérios de avaliação: jornada de trabalho de 40 horas em uma única escola; escola funcionando com recursos pedagógicos e financeiros suficientes, existência de professores para disciplinas/séries e pessoal administrativo e de apoio pedagógico, corpo docente efetivo; exercício da gestão com apoio de instâncias superiores e da comunidade, troca de informações com pares; satisfação com a carreira docente; e cargos e salários com remuneração condigna.

Destarte, considerando que as condições de trabalho podem determinar uma organização e gestão que limite a democratização da escola, apre- sentamos e discutimos os resultados encontrados na análise dos dados ora mencionados.

\section{Diretores e professores da rede estadual gaúcha: que condições de trabalho?}

Em De pernas pro ar, Galeano (1999) pressupõe de que, se Alice renascesse em nossos dias, não precisaria atravessar um espelho mágico, bastava chegar à janela; o mundo estaria às avessas. Segundo o autor, a publicidade manda consumir e a economia proíbe - um mundo que oferece o banquete a todos e fecha a porta no nariz 
de muitos. Em tempos de meritocracia e performance dos alunos vinculados a uma suposta qualidade docente, é necessário refletirmos sobre os dados que cotidianamente estão nas conversas e nos noticiários a respeito das escolas; sobretudo, dando visibilidade aos dados que são silenciados, ao que não é discutido, sequer dito. Analisamos, a seguir, os dados sobre condições de trabalho e carreira de diretores e professores do Rio Grande do Sul.

\section{Sobre a dimensão condições de trabalho}

A sobrecarga de trabalho merece um importante destaque nessa dimensão. $\mathrm{O}$ indicador de esforço docente (BRASIL, 2015 c) aponta que $52,9 \%$ dos professores da rede estadual gaúcha encontram-se entre os níveis mais elevados intensidade de trabalho: $4(39,4 \%), 5(10,2 \%)$ e $6(3,3 \%)$, ou seja, atuavam em dois ou mais turnos, em duas ou mais escolas, em duas ou mais etapas, atendendo de 50 a 400 alunos. Ademais, de acordo com o Censo da Educação Básica (BRASIL, 2017a), o percentual de professores dessa rede, nesses níveis de esforço docente, subiu para 54,5\% em 2017. As jornadas acumuladas podem ser explicadas, principalmente, pela busca de renda condigna, inclusive um novo contrato de trabalho quando já aposentados em um cargo.

Ratificam essa medida de esforço docente as respostas dadas pelos professores à questão "Em quantas escolas você trabalha?" sinalizando que, em 2017, 47,2\% trabalhavam em duas ou mais escolas (BRASIL, 2017b), ao passo que, em 2015, o percentual correspondia a 44\% (BRASIL, 2015b). Estes são os professores que, devido à organização curricular das escolas, possuem maior carga horária de trabalho na mesma instituição. Ademais, o Censo (BRASIL, 2017a) mostra que da totalidade dos professores estaduais gaúchos mais de 35\% não possui vínculo estável.

Com relação à carga de trabalho semanal, as respostas dadas aos questionários do diretor e do professor (BRASIL, 2017b) evidenciam sobrecarga, pois $13,8 \%$ dos diretores trabalham mais de 40 horas. No caso dos professores, apenas 5,2\% responderam que sua carga horária semanal na escola em que responderam ao questionário é maior do que 40 horas; no entanto, somente $38,3 \%$ cumprem jornada integral naquela mesma escola, ou seja, $61,7 \%$ dos professores trabalham também noutras escolas - o que pode ser bastante grave visto que os respondentes eram professores de disciplinas que usualmente têm maior carga horária. Ainda computando todas as escolas em que trabalham atualmente, $23,8 \%$ dos professores indicaram que a carga horária semanal é superior a 40 horas.

Esses dados devem ser confrontados com os parâmetros expressos na legislação, em especial na Lei do Piso Salarial do Magistério (BRASIL, 2008), que orienta aos docentes uma jornada integral de 40 horas semanais. Do contrário, conceitua-se como precarização da condição de trabalho docente (JACOMINI; PENNA, 2016).

Cabe destacar também que, em 2017, 30,5\% dos diretores exercem 
outra atividade remunerada além da direção das escolas, enquanto em 2015 o percentual era de $26,6 \%$. Ao observar os professores, nota-se uma situação mais problemática: $41,9 \%$ exercem outra atividade que contribui para a renda pessoal (BRASIL, 2017b). Isso confirma a necessidade de maior valorização profissional dos educadores, pois, como colocam Gatti e Barreto (2009), remuneração e carreira precisam corresponder à formação exigida e às responsabilidades sociais implicadas nesse trabalho.

De outra parte, Ball, Maguire e Braun (2016, p. 47-48) salientam que o período de trabalho de um professor pode determinar como se apodera de informações sobre a política ou não. Ressaltam que os contextos profissionais são multifacetados e confusos; e que vão sendo delineados concomitantemente aos fatores materiais, impactando e influenciando a efetividade das políticas. Assim sendo, acreditamos que trabalhar em mais de uma escola limita as possibilidades de perceber e contribuir na gestão democrática da instituição e na construção da política educacional.

Se a participação é uma dimensão fundante da gestão democrática, a dificuldade de participação do professor na gestão escolar, devido à sobrecarga e ao vínculo precário, pode se caracterizar como uma limitação da democracia. Fraser (2006) salienta que a paridade de participação é a materialização da justiça social, e que se as condições socioeconômicas não permitem a participação de um determinado grupo ou sujeito, políticas de redistribuição são necessárias. Como garantir voz para todos os membros se nem a presença é garantida em virtude da precária condição de trabalho? É preciso uma reestruturação que permita ao professor condições de exercer a docência de forma qualificada e, também, ocupar os espaços de discussão e tomada de decisão.

Em relação à condição de trabalho dos diretores, expressiva maioria respondeu que possui condições favoráveis de autonomia e trabalho coletivo (BRASIL, 2015b, 2017b), ainda que aproximadamente um terço dos respondentes tenha apontado a interferência de atores externos na gestão, o que pode ser um indicativo de práticas autoritárias em determinadas escolas. Os diretores ressaltaram o apoio da comunidade, apoio de instâncias superiores e troca de informações como aspectos importantes.

Um dado importante é que 40, $2 \%$ dos professores acreditam que os problemas de aprendizagem de seus alunos têm relação com sua sobrecarga de trabalho; enquanto $41,7 \%$ dos professores os atribui a insatisfação e desestímulo com a carreira docente (BRASIL, 2017b). Quanto a problemas de funcionamento da escola, a maioria dos diretores salienta a insuficiência de recursos financeiros e a indisciplina por parte dos alunos (BRASIL, 2015b, 2017b).

A percepção dos professores e diretores quanto às dificuldades enfrentadas nos provocam a pensar sobre a ênfase da gestão das escolas: a prevalência dos aspectos financeiros não prejudica a atenção às atividades finalísticas, à qualidade da educação? Com efeito, há precariedade em muitos es- 
paços escolares, bem como insuficiência de materiais necessários a um trabalho pedagógico de melhor qualidade, causando preocupação aos profissionais à frente da gestão. Aliás, Ball, Maguire e Braun (2016, p. 64-65) salientam que as análises de políticas precisam incorporar a realidade das escolas, "com seus contextos situados e materiais, suas culturas e desafios profissionais específicos, e suas pressões e seus apoios externos diferentes". Portanto, esses elementos contextuais precisam ganhar visibilidade e serão discutidos seguir.

\section{Sobre a dimensão carreira e remuneração}

O primeiro diagnóstico sobre a carreira está na observação do envelhecimento dos profissionais em atividade. De acordo com o Censo da Educação Básica (BRASIL, 2017a), 39,5\% dos professores da rede estadual gaúcha possuem 50 anos ou mais; docentes com idade igual ou superior a 40 anos perfazem um total de 70,8\%. Em relação às redes federal, municipal e privada do mesmo estado, fica evidente que a rede estadual possui professores mais velhos; nas escolas privadas, por exemplo, $49 \%$ dos professores se encontram na faixa etária de 40 anos ou mais.

A situação sugere que a carreira do magistério público estadual tem sido pouco atrativa para as novas gerações. Tal movimento pode estar relacionado à precariedade das condições de exercício da profissão - já observadas neste estudo - aliada à baixa valorização social (FUNDAÇÃO VAR-
KEY, 2018). Nesse contexto, é necessário pensarmos sobre como os diretores e professores se constituem como profissionais e constroem suas subjetividades. Nunes e Oliveira (2017, p.71) salientam a importância de possibilitar uma carreira docente que seja atrativa aos jovens, para que a profissão seja parte de seus projetos de vida e não a única opção por não conseguirem bons resultados em cursos de maior reconhecimento social.

A respeito da remuneração, o salário dos profissionais da rede estadual gaúcha tem sido posto em grande evidência porque consta ser o menor do país $^{9}$ e sem reajuste desde 2015. Cotejando as informações dos diretores com as dos professores sobre a remuneração, obtivemos a Tabela 1. Constata-se que $69,1 \%$ dos diretores recebem salários entre $R \$ 2.811,01 \mathrm{e}$ $\mathrm{R} \$$ 6.559,00. Em contrapartida, nessa mesma faixa salarial, encontram-se apenas 29,9\% dos professores. Cumpre esclarecer que há previsão legal de gratificação pelo exercício da função de diretor e Gratificação de Gestão de Estabelecimento Relativamente Autônomo (RIO GRANDE DO SUL, 2003) que, conforme estudo realizado por Marques, Andrade e Moreira (s/d), juntos podem corresponder ao valor máximo de $\mathrm{R} \$$ 995,04 adicionais.

\footnotetext{
${ }^{9}$ PISO salarial dos professores no Brasil. Gazeta do Povo. 05 de abril de 2019. Disponível em:

https://infograficos.gazetadopovo.com.br/educ acao/piso-salarial-professor-no-brasil.
} 
Tabela 1 - Comparação entre salário bruto recebido pelo diretor com o salário bruto recebido pelo professor da rede estadual de educação do Rio Grande do Sul, 2017

\begin{tabular}{|c|c|c|}
\hline Variável & $\begin{array}{l}\mathrm{n}=2.010 \\
\mathrm{n}(\%)\end{array}$ & $\begin{array}{l}\mathrm{n}=16.094 \\
\mathrm{n}(\%)\end{array}$ \\
\hline Salário bruto (com adicionais, se houver) & Diretores & Professores \\
\hline Até $\mathrm{R} \$ 937,00$ & $52(2,8)$ & $121(1,8)$ \\
\hline $\mathrm{R} \$ 937,01$ a $\mathrm{R} \$ 1.405,50$ & $47(2,5)$ & $986(14,3)$ \\
\hline $\mathrm{R} \$ 1.405,51$ a $\mathrm{R} \$ 1.874,00$ & $130(6,9)$ & $1.181(7,3)$ \\
\hline $\mathrm{R} \$ 1.874,01$ a $\mathrm{R} \$ 2.342,50$ & $166(8,9)$ & $1.587(23,1)$ \\
\hline $\mathrm{R} \$ 2.342,51$ a $\mathrm{R} \$ 2.811,00$ & $185(9,9)$ & $952(13,8)$ \\
\hline $\mathrm{R} \$ 2.811,01$ a $\mathrm{R} \$ 3.279,50$ & $346(18,5)$ & $812(11,8)$ \\
\hline $\mathrm{R} \$ 3.279,51$ a $\mathrm{R} \$ 3.748,00$ & $318(17,0)$ & $483(7,0)$ \\
\hline $\mathrm{R} \$ 3.748,01$ a $\mathrm{R} \$ 4.685,00$ & $434(23,1)$ & $507(7,4)$ \\
\hline $\mathrm{R} \$ 4.685,01$ a $\mathrm{R} \$ 6.559,00$ & $197(10,5)$ & $252(3,7)$ \\
\hline NR & 135 & 9.213 \\
\hline
\end{tabular}

Fonte: Questionários do Diretor e do Professor (BRASIL, 2017b).

A maior remuneração dos diretores em relação aos professores está em conformidade com o apresentado por Souza e Gouveia (2010), justificada pela singularidade da função. Afinal, a prática da gestão escolar exige dos diretores uma dedicação maior, que abarca as dimensões administrativa, pedagógica e política. Todavia, no caso de nosso estudo, a diferença excede o valor pago pela função gratificada - ou seja, possivelmente os profissionais em cargos de direção são melhor remunerados porque agregam o tempo de serviço e outras gratificações, como abono de difícil acesso, previstas no plano de carreira. Também, pode-se considerar que um percentual importante de diretores tenha duas matrículas e já esteja aposentado em uma delas, tendo ampliação da carga horária (e de remuneração, consequentemente) em seu vínculo ativo. Entretanto, são necessários outros es- tudos para confirmar ou refutar tais hipóteses.

Os dados provenientes dos questionários (BRASIL, 2017) também mostram que os professores e diretores que se encontram nas maiores faixas salariais (a partir de R \$2.811,01) são, majoritariamente, aqueles com 10 ou mais anos docência e com especialização (pós-graduação com no mínimo 360 horas). Do total de respondentes, 97,6\% dos diretores e 95,6\% dos professores possuem graduação; $82,3 \%$ dos diretores e $66,8 \%$ dos professores realizaram estudos de pós-graduação. Alertamos que o plano de carreira estadual (RIO GRANDE DO SUL, 1974) é muito antigo e tem como última valorização o curso de especialização, sem incentivar profissionais que possuem mestrado e doutorado. Há, neste caso, quem receba menos do que $\mathrm{R} \$ 2.811,01$. Observamos que $21,8 \%$ dos diretores e $64,1 \%$ dos professores que possuem mestrado e 
$12,5 \%$ dos diretores e $77 \%$ dos professores com doutorado estão nesta faixa de remuneração.

Relacionando as respostas dos diretores às questões sobre o salário bruto e a carga horária semanal, na Tabela 2, notamos que $25,9 \%$ dos diretores que trabalham 40 horas semanais têm salário bruto na faixa compreendida entre $\mathrm{R} \$$ \$ 3.748,01 e $\mathrm{R} \$ 4.685,00$.
Supondo que recebem o valor máximo ( $\mathrm{R} \$ 4.685,00)$ para, aproximadamente, 200 horas mensais, o valor da hora trabalhada seria de $\mathrm{R} \$ 23,43$, i.e. abaixo do que recebem outros profissionais com curso superior. Pior, 62\% dos diretores que trabalham 40 horas semanais declararam faixas salariais inferiores a essa, assim como é o salário bruto dos professores.

Tabela 2 - Relação entre salário bruto e carga horária de trabalho semanal dos diretores das escolas estaduais do Rio Grande do Sul, 2017

\begin{tabular}{lcrrr}
\hline Salário bruto do diretor. & \multicolumn{3}{l}{ Carga horária de trabalho semanal, como diretor, nesta } \\
& escola & & & \\
\hline & + de 40h & $\mathbf{4 0 h}$ & De 20 a 39h & - de 20h \\
& $\mathrm{n}(\%)$ & $\mathrm{n}(\%)$ & $\mathrm{n}(\%)$ & $\mathrm{n}(\%)$ \\
\cline { 2 - 5 } Até R\$ 937,00 & $13(5,2)$ & $34(2,4)$ & $05(2,5)$ & $00(0,0)$ \\
R\$ 937,01 a R\$ 1.405,50 & $06(2,3)$ & $18(1,3)$ & $22(10,6)$ & $01(14,3)$ \\
R\$ 1.405,51 a R\$ 1.874,00 & $23(8,9)$ & $52(3,7)$ & $51(24,6)$ & $03(42,8)$ \\
R\$ 1.874,01 a R\$ 2.342,50 & $17(6,6)$ & $105(7,5)$ & $43(20,8)$ & $01(14,3)$ \\
R\$ 2.342,51 a R\$ 2.811,00 & $20(7,8)$ & $136(9,7)$ & $28(13,5)$ & $00(0,0)$ \\
R\$ 2.811,01 a R\$ 3.279,50 & $44(17,1)$ & $274(19,5)$ & $27(13,1)$ & $01(14,3)$ \\
R\$ 3.279,51 a R\$ 3.748,00 & $57(22,2)$ & $251(17,9)$ & $10(4,8)$ & $00(0,0)$ \\
R\$ 3.748,01 a R\$ 4.685,00 & $53(20,6)$ & $363(25,9)$ & $17(8,2)$ & $01(14,3)$ \\
R\$ 4.685,01 a R\$ 6.559,00 & $24(9,3)$ & $169(12,1)$ & $04(1,9)$ & $00(0,0)$ \\
TOTAL & $\mathbf{2 5 7 ( 1 0 0 , 0 )}$ & $\mathbf{1 . 4 0 2}(\mathbf{1 0 0 , 0})$ & $\mathbf{2 0 7}(\mathbf{1 0 0 , 0})$ & $\mathbf{0 7}(\mathbf{1 0 0 , 0})$ \\
\hline NR & & & $\mathbf{1 3 7}$ \\
\hline Fonte: Questionário do Diretor (BRASIL, 2017b).
\end{tabular}

Esta situação crítica está situada no contexto nacional em que o relatório "As Desigualdades na Escolarização no Brasil" (CONSELHO DE DESENVOLVIMENTO ECONÔMICO E SOCIAL, 2014) posiciona o rendimento médio dos professores como equivalente a $51,7 \%$ do obtido pelos demais profissionais com nível superior completo. Já os dados do Instituto Brasileiro de Geografia e Estatística (BRASIL, 2015a) indicam que tanto Brasil quanto no Rio Grande do Sul, em 2013, a renda média real foi maior para os níveis de escolaridade mais altos; mas que o valor pago a professores por hora trabalhada correspondia a $\mathrm{R} \$ 18,00$ enquanto outros profissionais com curso superior recebiam $\mathrm{R} \$ 29,00$ e os profissionais da saúde $\mathrm{R} \$ 35,00$. Essa informação é corroborada por um estudo realizado pelo Instituto Nacional de Estudos e Pesquisas Educacionais Anísio Teixeira que aponta que professores com nível superior têm remuneração 39\% menor do que outros profissionais com 
a mesma escolaridade ${ }^{10}$. À vista disso, é notória a importância da Meta 17 do PNE (BRASIL, 2014b) que visa à equiparação do rendimento médio dos profissionais do magistério das redes públicas com outras categorias profissionais de nível superior. Para avançar na valorização dos trabalhadores em educação, as estratégias previstas abrangem a implantação do piso salarial e programas que garantam oportunidades de desenvolvimento pessoal e profissional.

Contudo, é preciso refletir sobre como e em que medida as condições de trabalho são equacionadas perante os fins da educação e as especificidades político-pedagógicas da escola, pois os salários de diretores e professores da rede estadual gaúcha não correspondem a uma carreira condigna em que qualidade de educação e qualidade de vida do docente estejam imbricadas. Ademais, no Governo Sartori (2015-2018), no qual foram produzidos os dados aqui estudados, a precarização da profissão foi potencializada pela ausência de concurso, pelo aumento das contratações temporárias, pelo fechamento de escolas, pelo não pagamento dos salários em dia e por ações com a intenção de cobrir a ausência de professores por licença médica e, ainda, substituir grevistas por voluntários sem formação específica (RIO GRANDE DO SUL, 2017). Pa-

10 PROFESSOR recebe até $39 \%$ menos que profissional com igual escolaridade. Folha de São Paulo. 14 de junho de 2016. Disponível em:

https://www1.folha.uol.com.br/educacao/2016 /11/1832095-professor-recebe-ate-39-menosque-profissional-com-igual-

escolaridade.shtml. Acesso: 19/12/2019. rece evidente que tais práticas ferem o princípio da valorização dos profissionais da educação, ignoram marcos legais e o plano de carreira, exigindo estudos e decisões para superar as condições de desestímulo à profissão e à dedicação ao ensino de qualidade.

\section{Algumas considerações e muito a pensar!}

Ao investigar elementos referentes à gestão escolar e ao exercício profissional na rede estadual de ensino do Rio Grande do Sul, que ganharam visibilidade a partir do questionário do SAEB (2017b), foi possível confirmar imbricações - mas também possíveis controvérsias - entre aspectos que alinhamos como condições objetivas e subjetivas de trabalho: quadro de pessoal relativamente envelhecido; elevada carga de trabalho; precários vínculos de carreira, com muitos professores não concursados e temporários; e baixa remuneração em geral - fatores de insatisfação com a situação de trabalho, aos quais $40 \%$ dos professores creditam influência nos problemas de aprendizagem dos alunos. Com efeito, notamos que, dentre os professores, $20 \%$ trabalham mais de 40 horas por semana, 47,2\% atuam em duas ou mais escolas e, ainda, que parte dos diretores exerce outra atividade remunerada.

No entanto, a maioria dos diretores manifesta relativa satisfação com sua experiência profissional: não sofre interferências externas no exercício da função; recebe apoio de instâncias superiores e da comunidade; e troca informações com seus pares. Indicam 
que os problemas que mais dificultam o funcionamento da escola são a insuficiência de recursos financeiros e a indisciplina por parte dos alunos.

Consideramos, então, importante divulgar estes resultados e recomendar estudos mais aprofundados sobre as relações entre os diversos condicionantes já identificados nos atuais instrumentos de censo e avaliação escolar, assim como entre os aspectos associados a condições objetivas e subjetivas de trabalho dos professores e diretores. Alguns dados nos sugerem convergências e diferenças de percepção, que merecem ser mais investigadas. A diversidade de condições de trabalho e manifestações de professores e diretores, entre as unidades escolares de uma mesma rede pública ou entre as redes que se sobrepõem num mesmo território federativo, ainda requer análises inferenciais.

Contudo, é latente a necessidade de pensar a escola como um ambiente educativo onde trabalhar, estudar e formar não sejam atividades desconectadas. $\mathrm{O}$ sistema educacional precisa se constituir em uma cultura que associe formação e atuação à valorização dos profissionais da educação - o que inclui carreira, salário e condições de trabalho. Estes são elementos já conhecidos da agenda de produção das políticas educacionais, visto que "o contexto é um fator mediador no trabalho de atuação de políticas feito nas escolas - e é único para cada escola" (BALL, MAGUIRE, BRAUN, 2016, p.63). Assim, esses autores salientam que as políticas educacionais não são simplesmente implementadas pelos profissionais em exercício nas escolas; estas são, de fato, o lócus privilegiado de produção das políticas, sempre entremeadas por um conjunto de dimensões contextuais.

Não obstante, há limitação de informações oficiais sobre os profissionais da educação que não estão atuando em sala de aula - no Censo - e os que não lecionam Português e Matemática - no SAEB. Além disso, o único instrumento que os diretores respondem é o questionário do SAEB; no Censo, não há instrumento específico para eles, nem para os funcionários das escolas.

Cabe, por fim, refletirmos que a desvalorização da carreira - financeira e socialmente - desdobra-se num ciclo que implica a qualidade da educação: carreira pouco atrativa corrobora para que deficiências de formação se perpetuem na prática cotidiana das nossas instituições. A insatisfação dos professores com questões salariais e condições de trabalho compromete os conhecidos desafios das escolas públicas. É preciso enfrentar esses problemas! Ademais, a gestão democrática, uma conquista do longo processo de redemocratização do país, frente ao presente estado da política pode sofrer um esvaziamento de sentido. Sua prática exige formação, vivências de discussão e tomada de decisões coletivas, que dependem também de tempo e espaço qualificado. 


\section{Referências}

BALL, Stephen J.; MAGUIRRE, Meg; BRAUN, Annette. Como as escolas fazem as políticas: atuação em escolas secundárias. Ponta Grossa: Editora UEPG, 2016, 230p.

BRASIL. Lei n ${ }^{\circ}$ 9.394, de 20 de dezembro de 1996. Estabelece as diretrizes e bases da educação nacional. Brasília: 1996. Disponível: https://www2.senado. leg.br/bdsf/bitstream/handle/id/70320/65.pdf. Acesso: 24/12/2019.

BRASIL. Lei no 11.738, de 16/7/2008 - Piso Salarial Profissional Nacional. Brasília: 2008. Disponível: https://bit.ly/1mHCUdN. Acesso: 14/03/19.

BRASIL. MEC. CNE. Resolução CNE/CEB nº 2, de 28 de maio de 2009. Fixa as Diretrizes Nacionais para os Planos de Carreira e Remuneração dos Profissionais do Magistério da Educação Básica Pública. Brasília, 2009. Disponível: http://portal.mec.gov.br/dmdocuments/resolucao_cne_ceb002_2009.pdf. Acesso: 24/12/2019.

BRASIL. PNE, 2014. Lei n. 13.005, de 25 de junho de 2014. Brasília: 2014b. Disponível: https://bit.ly/1LbcL4B. Acesso: 14/03/19.

BRASIL. IBGE. Pesquisa nacional por amostra de domicílios: síntese de Indicadores 2015. Rio de Janeiro: IBGE, 2016. 108p. PNAD, 2015a. Disponível: https://bit.ly/2rqiYEB. Acesso: 14/03/19.

BRASIL. MEC. INEP. SAEB: microdados. 2015. Brasília: 2015b. Disponível: https://bit.ly/2IsErWA. Acesso: 14/03/19.

BRASIL. MEC. INEP. Indicador de Esforço Docente. 2015. Brasília: 2015c. Disponível:https://bit.ly/2IcIpmX. Acesso: 14/03/19.

BRASIL. MEC. INEP. Censo da Educação Básica: microdados. Brasília: 2017a. Disponível:https://bit.ly/2v8jcSp. Acesso: 14/03/19.

BRASIL. MEC. INEP. SAEB: microdados. 2017. Brasília: 2017b. Disponível: https://bit.ly/2D7bo7O. Acesso: 14/03/19.

BRASIL. MEC. INEP. Indicador de Esforço Docente. 2017. Brasília: 2017c. Disponível: https://bit.ly/2Ic6B95. Acesso: 14/03/19.

BRASIL. MEC. INEP. Resultados finais do Censo da Educação Básica. Brasília: 2017d. Disponível: https://bit.ly/2Fkn6vZ. Acesso: 14/03/19.

CARVAlHO, Cynthia Paes de; WALDHELM, Andrea Paula de Souza; ALVES, Fátima; KOSLINSKI, Mariane. Gestão e desempenho escolar: um estudo nas redes municipais da região metropolitana do Rio de Janeiro a partir dos resultados da 
Prova Brasil 2009. ANPAE, III Congresso Iberoamericano de Política e Administração da Educação. Espanha: 2012. Disponível: https://bit.ly/2EV1y76. Acesso: 26/03/19.

CONSELHO DE DESENVOLVIMENTO ECONÔMICO E SOCIAL. Relatório de Observação $n^{\circ}$ 5. As desigualdades na escolarização no Brasil: relatório de observação no 5. Brasília: 2014. 60 p. Disponível: https://bit.ly/2TkslRn. Acesso: 21/02/19.

CORREA, V. S. Gestão escolar e gênero: o fenômeno do teto de vidro na educação brasileira. Dissertação (Mestrado em Educação) - Universidade Federal do Paraná, Curitiba, 2010. Disponível em: https://bit.ly/2Top82Y. Acesso: 10/03/19.

CUNHA, Maria Isabel da. Aprendizagem da docência em espaços institucionais: é possível fazer avançar o campo da formação de professores? Avaliação, Campinas, Nov./2014, vol.19, $\mathrm{n}^{\circ}$ 3, p. 789-802. Disponível: https://bit.ly/2HLEI7B. Acesso: 16/03/19.

FRASER, N. La justicia social en la era de la política de la identidad: Redistribuición, reconocimiento y participación. In.: FRASER, N.; HONNETH, A. Redistribución o reconocimiento? Un debate político-filosófico. Madrid: Morata, 2006.

FUNDAÇÃO VARKEY. Global Teacher Status Index: Brasil: 2018. Disponível em: https://www.varkeyfoundation.org/media/4833/gtsi-brazil-chart-findings.pdf. Acesso: 19/12/2019.

GALEANO, Eduardo. De pernas pro ar: a escola do mundo ao avesso. Tradução de Sérgio Faraco. 6a . Edição. Porto Alegre: L\&PM, 1999. 386 p.

GATTI, B. A.; BARRETO, E. de S. Professores do Brasil: impasses e desafios. Brasília: 2009. Disponível: https://bit.ly/1i4Baop. Acesso: 24/03/19.

JACOMINI, Márcia Aparecida; PENNA, Marieta Gouvêa de Oliveira. Carreira docente e valorização do magistério: condições de trabalho e desenvolvimento profissional. Pro.posições, v. 27, n. 2 (80), maio/ago. 2016. Disponível: https://bit.ly/2WfClgp. Acesso: 26/03/19.

MARQUES, Albertina Gioconda de Moraes; ANDRADE, Gislaine Rodrigues de; MOREIRA, Marilan de Carvalho. Remuneração do diretor de escola na rede pública estadual de educação do RS. Porto Alegre: s/d. Disponível: https://bit.ly/2Oh1815. Acesso: 14/02/19. 
NUNES, Claudio Pinto; OLIVEIRA, Dalila Andrade. Trabalho, carreira, desenvolvimento docente e mudança na prática educativa. Educ. Pesqui., São Paulo, v. 43, n.1, p. 65-80, jan./mar. 2017. Disponível: https://bit.ly/2xNI96s. Acesso: 04/04/19.

OLIVEIRA, Dalila Andrade. A reestruturação do trabalho docente: precarização e flexibilização. Educ. Soc., Vol. 25, n. 89, p. 1127-1144, Set./Dez. 2004. Disponível: https://bit.ly/2KcagQG. Acesso: 22/03/19.

RIO GRANDE DO SUL (RS). Lei No 12.028, de 18 de dezembro de 2003. Dispõe sobre a gratificação pelo exercício de direção de estabelecimento de ensino. Porto Alegre: 2003. Disponível: https://bit.ly/2OiBn0e. Acesso: 21/03/19.

RIO GRANDE DO SUL (RS). Portaria no. 285/2017. Dispõe sobre a regulamentação do Serviço Voluntário no âmbito da Secretaria Estadual da Educação. Porto Alegre: 2017. Disponível: https://bit.ly/2U1j2Kj. Acesso: 21/03/19.

RIO GRANDE DO SUL (RS). Estatuto e Plano de Carreira do Magistério Público do Rio Grande do Sul, Lei no. 6.672/1974. Porto Alegre: 1974. Disponível: https://bit.ly/2Q2rIv8. Acesso: 12/02/19.

SOUZA, A. R. Perfil da Gestão da Escola no Brasil. Tese (Doutorado em Educação). São Paulo: PUC-SP, 2007. Disponível: https://bit.ly/2ERbwGx. Acesso: 30/03/19.

SOUZA, A. R.; GOUVEIA, A. B. Diretores de escolas públicas: aspectos do trabalho docente. Educar em Revista, Curitiba, Brasil, n. especial 1, p. 173-190, 2010. Editora UFPR. Disponível: https://bit.ly/2HSKhhW. Acesso: 21/03/19.

VIEIRA, Sofia Lerche; VIDAL, Eloisa Maia. Gestão democrática da escola no Brasil: desafios à implementação de um novo modelo. Revista Iberoamericana de Educación. N. ${ }^{o} 67$ (2015), p. 19-38. OEI/CAEU: 2014. Disponível: https://bit.ly/2JQTB6h. Acesso: 16/03/19.

O(s) autor(es) se responsabiliza(m) pelo conteúdo e opiniões expressos no presente artigo, além disso declara(m) que a pesquisa é original.

Recebido em 23/03/2020

Aprovado em 12/06/2020 